\title{
Pilot plant study of dry deposition of paste tailings in Baogang West Mine
}

\author{
Yueguang Che Kunming PSEI Mining Engineering Company Ltd, China \\ Man Feng Kunming PSEl Mining Engineering Company Ltd, China
}

Tianzhu Xue Kunming PSEI Mining Engineering Company Ltd, China

\begin{abstract}
In order to understand the deposition of paste tailings, laboratory and pilot plant tests were conducted on iron ore tailings from Baogang Baiyun E'Bo West Mine. Relevant experiments include those of tailings rheology, pilot plant thickening, flume and consolidation, the stimulation of the properties of dust suppression and flood scouring resistance, and so on. The study reveals the technical feasibility of the dry-type deposition of high density or paste iron ore tailings from Baogang Baiyun E'Bo West Mine. The existing thickening techniques can produce the required concentration of tailings for paste deposition. It also shows that after being discharged into the tailings disposal site, the tailings will present desirable behaviours of consolidation, dust suppression and flood scouring resistance.
\end{abstract}

\section{Introduction}

An iron ore beneficiation system is being expanded at the West Mine of Baotou Iron and Steel Co, Ltd is West Mine, with an annual tailings production between 7 million tons and 210 million tons during its 30 years of design life.

For the West Mine tailings, if transported and disposed at the conventional low concentration, the following major problems are likely to occur:

- If the elevation of the perimeter embankment is $1602 \mathrm{~m}$ (i.e. $5^{\sim 10} \mathrm{~m}$ high), the tailings storage facility (TSF) will be filled within 12 years;

- The annual average evaporation amount in the local area is $2100 \mathrm{~mm}$. If the tailings are discharged into the tailings pond with low concentration and with the surface water area of $2 \mathrm{~km}^{2}$, the water will evaporate at the rate of 3 million $\mathrm{m}^{3}$ per year, increasing the production cost by some 2.2 million US\$.

However, the disposal of tailings at high density will result in the following advantages:

- With the perimeter embankment at an elevation of $1602 \mathrm{~m}$ on the downstream side and $1607 \mathrm{~m}$ on the upstream side, the TSF will be filled in 30 years;

- Because little or even no bleed water is stored in the TSF, the evaporation loss of the process water is low. The majority of the process water will be recycled to the beneficiation plant in the form of thickener overflow for reuse.

- After deposition in the TSF, the highly thickened tailings will dry and densify, thus increasing the safety and stability of the embankment. 
With the dual objectives of enhancing the TSF safety and saving water, after a thorough research and site visits to some of the built projects, the dry-type surface disposal method of high density tailings (paste) is chosen. A design company and a thickener vendor is contracted to conduct rheology, thickening and flume tests on the West Mine tailings.

\section{Test objectives}

The testing program was designed to verify the technical feasibility of dry-type surface disposal of the high density or paste tailings of West Mine tailings, and meanwhile collect the data to be used for the later design of tailings dewatering, transportation and TSF.

The following objectives were proposed for the testing program:

- Rheology tests are conducted to determine the concentration of the high density or paste tailings to be discharged into the TSF for deposition.

- With the underflow concentration data obtained from the rheology tests, sizing tests of thickener are conducted for itspreliminarily selection.

- Pilot plant tests with the selected thickener are carried out to determine the parameters of feeding slurry, flocculants, overflow and underflow, and etc.

- Flume tests on the underflow of the thickeners are performed to determine the properties of tailings after deposition in TSF, including the flow regime of the slurry in the TSF, the angle of repose, segregation or not, etc.

- A qualitative analysis is conducted on the thickened tailings to examine the characteristics of consolidation, dust suppression and flood scouring resistance.

\section{Test overview}

\subsection{Rheology tests}

Using a Haake VT550 viscometer, the rheology tests were conducted to measure the rheology properties of the tailings slurry at its applicable concentration to estimate the required yield stress for the high density or paste tailings, as well as the viscosity parameters of the slurry, in the hope of providing the design parameters for the slurry transportation design.

\subsection{Pilot plant thickening tests}

Based on the slurry properties and the concentration rate required for the high density or paste tailing deposition, the pilot plant study was conducted with the recommended thickener with the aims to:

- make sure the thickener can generate the required concentration of underflow for the surface disposal of the high density or paste tailings under the actual production conditions.

- identify the properties of the feeding slurry, including the solids content, particle size distribution, etc. and determine the optimum concentration of the feeding slurry.

- verify the type and dosage of the flocculants.

Figure 1 shows the major equipment, a pilot-scale thickener (with a diameter of $1 \mathrm{~m}$ ), used for sizing test. 


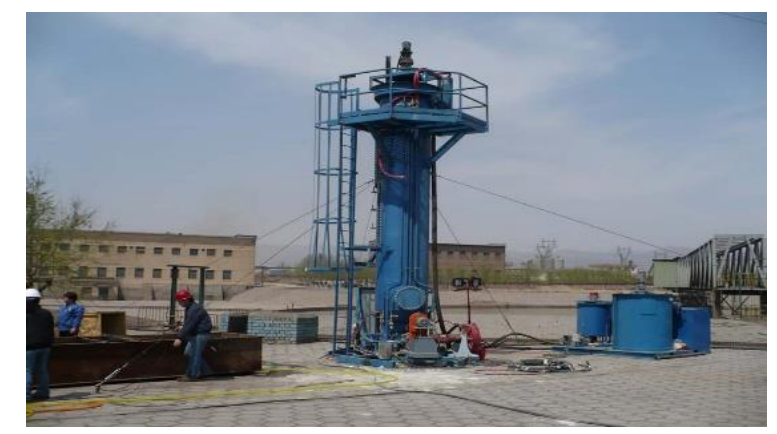

Figure 1 Pilot-scale thickener

\subsection{Flume tests}

Flume tests were conducted on the underflow slurry in the thickener that met the requirements for the drytype disposal of high density or paste tailings. The test estimated the related characteristics of the tailings discharged into the TSF, especially that of the beach slope (angle of repose), flow regime and segregation.

\subsection{Tests on the thickened tailings in the TSF}

After deposition in the TSF for a certain period of time, this test is a qualitative observation of the dry and solidifying status, the dust suppression ability and flood scouring resistance after consolidation of the paste tailings.

\section{$4 \quad$ Results and discussion}

\subsection{Rheological property analysis}

The rheology test results show that when the tailings slurry concentration is over $65 \%$, the yield stress and viscosity coefficient start to rise dramatically (see Figure 2). Above this concentration, no more solids segregation appears during deposition. When the slurry concentration reaches $73.3 \%$, the yield stress is 50 $\mathrm{Pa}$ and low yield stress paste appear in the tailings. The above data show that the slurry concentration required for the dry-type surface disposal of the high density or paste tailings should be above $70 \%$. The design concentration of the tailings for dry-type deposition of the tailings was set at $73 \%$. The focus of the sizing test of the thickener is to verify the ability of producing the underflow with concentration up to $73 \%$, or at least above $70 \%$.

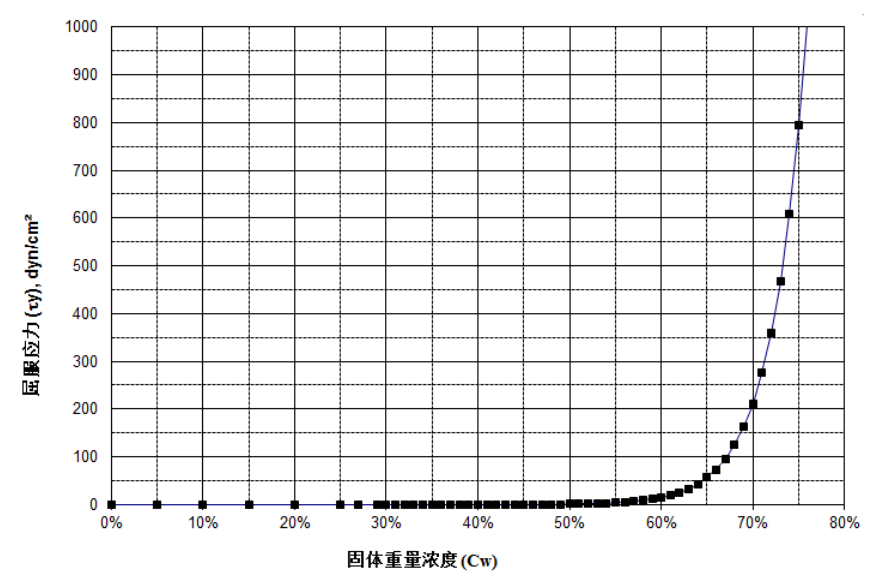

Figure 2 Slurry yield stress versus solids concentration

\subsection{Pilot plant testing result analysis}

The pilot plant tests of the tailings thickener in Baogang investigated two different bed depths $(1.5$ and $3 \mathrm{~m}$, respectively) and thickening effects of different residence time of solids in the thickener. During the tests, 
the thickener was operated fora considerably long time to ensure all the solids in the bed were replaced after the change of operation conditions. The average underflow solids concentration by weight for the steady state operation was plotted versus the solids residence time as shown in Figure 3.

For the prescribed $1.5 \mathrm{~m}$ high bed, three residence times tests were conducted showing that the underflow concentration increases with an increase in solids residence time. When the solids residence time increases from 4 hours to 10 hours, the underflow concentration increases from 71.3 to $73.5 \%$ correspondingly.

For the prescribed $3 \mathrm{~m}$ high bed, when the solids residence time is 6 hours, the underflow concentration can reach 73.3\%; however, when the residence time increases to 12 hours, the measured underflow concentration is significantly less than was anticipated.

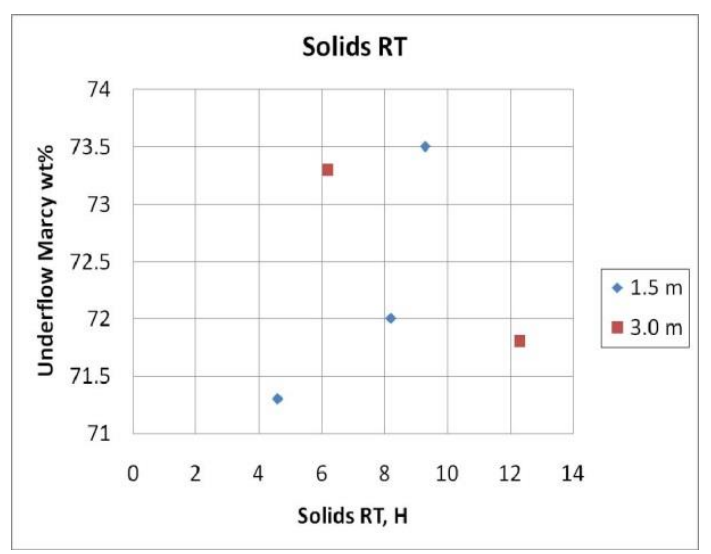

Figure 3 Sizing tests result for residence time and mud depth

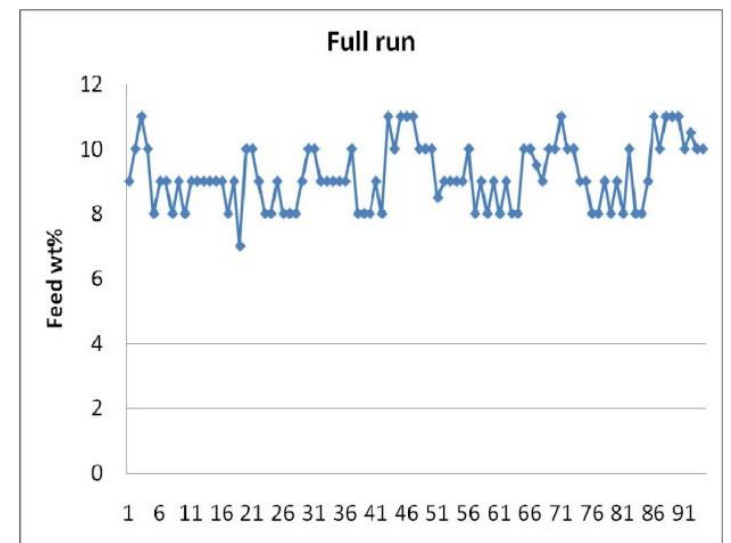

Figure 4 Variation curve of the feed slurry solids concentration

A comprehensive analysis of the testing data draws the following conclusions:

- For Baogang West Mine tailings, the underflow concentration could reach 71 74\% using the deep cone thickener technology.

- The depth of the bed level in the thickener should be greater than $3 \mathrm{~m}$. An increase in the mud bed depth will serve to increase the underflow concentration.

- Extended solids residence time in the thickener is not required to increase the underflow solids concentration. The testing data show when the depth of mud bed is $3 \mathrm{~m}$, an extended solids residence time does not raise the underflow concentration, but lowers it instead.

- Within the variation range of feed slurry solids concentration (see Figure 4), all the produced underflow concentration can reach the anticipated value.

- The pilot plant tests also investigated the influence of different types of flocculants and eventually selected flocculant SNF 936. With the variation in the characteristics of the feed slurry, the flocculant 
dosage varied. The tests revealed that by adding flocculants, the thickener can produce the underflow concentration required for the dry-type deposition of the high density or paste tailings.

\subsection{Flume tests result analysis}

Simulation flume tests were conducted on the paste tailings to be discharged into the TSF so as to identify the paste flow regime, angle of repose and to check its segregation after it is discharged into the TSF for surface disposal.

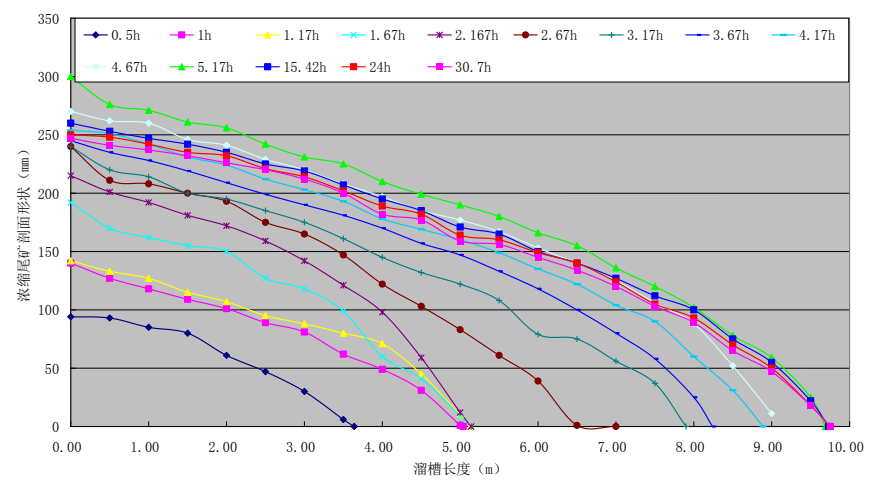

Figure 5 Profile of the paste tailings flow in the flume

The measured profile of the thickened tailings in the flume after deposition is shown in Figure 5. It shows that the thickened tailings with concentration of over $73 \%$ will form a natural slope of $2 \sim 2.5 \%$ after deposition in the flume.

Through the qualitative observation, it was found that during the paste tailings deposition in the flume, only a flow regime was found to appear in the surface layer and no flow trench was formed.

The PSD tests result of the samples collected from different positions $(0,1,5$ and $9.5 \mathrm{~m})$ of the flume showed that the paste tailings solids particles did not segregate during the flow.

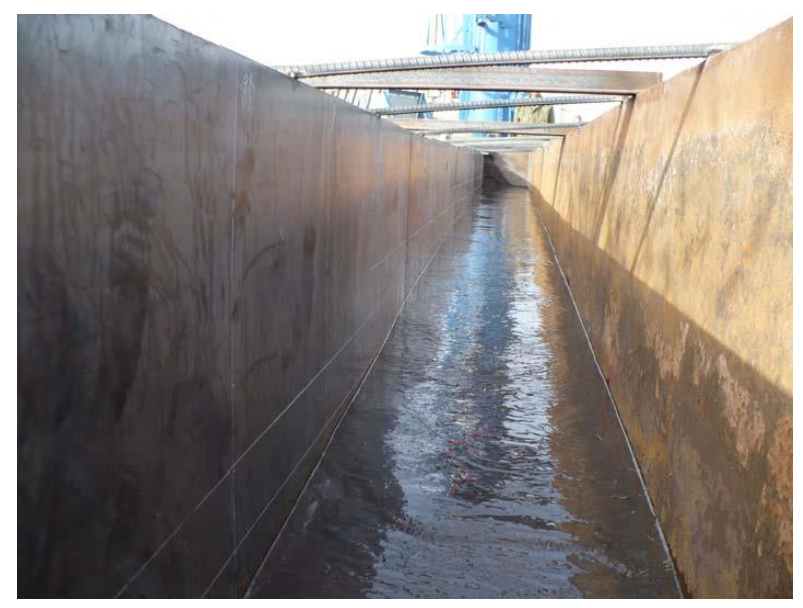

Figure 6 Flow regime of the tailings $73 \% \mathrm{Cw}$ in the flume

\subsection{Flood scouring tests}

The original concentration of the thickened tailings used for tests was $73 \%$. After 7 days' displacement in the open air, during which no rain fall occurred, the tailings dried and desiccated, as shown in Figure 7, resulting in a good resistance to dust generation if not physically disturbed. 


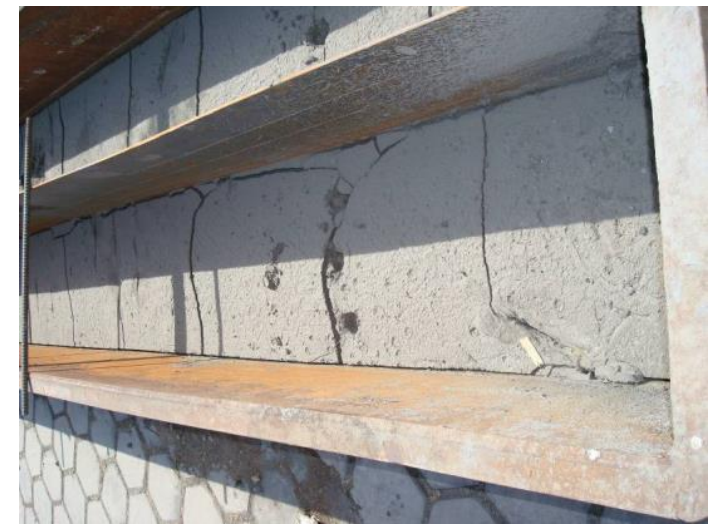

Figure 7 Desiccated tailings

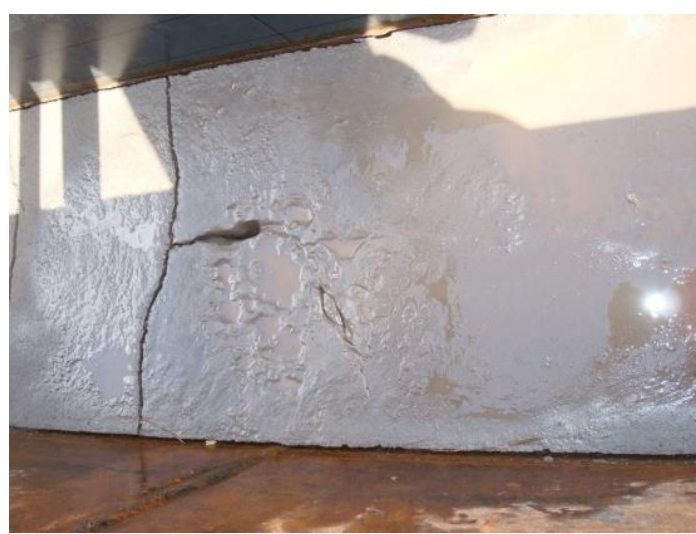

Figure 8 Tailings after being flooded by a $500 \mathrm{~mm}$ rainfall

A heavy rain storm was simulated to conduct a flood scouring test on the tailings after 7 days of consolidation. No wash-out was found to appear in the flume, as shown in Figure 8.

\section{$5 \quad$ Conclusions}

The following conclusions can be drawn from the rheological analysis, the pilot plant thickening study, the flume tests and the tests of desiccation drying, dust suppression and flood scouring tests on Baogang West Mine tailings:

- For the dry-type surface disposal of Baogang West Mine high density or paste iron ore tailings, the required slurry concentration should be above $70 \%$. Hence, the design concentration is $73 \%$.

- For Baogang West Mine iron ore tailings, the deep cone thickener technology can generate an underflow concentration of $72 \sim 74 \%$.

- The paste tailings after deposition in the TSF can form an angle of repose of $2 \sim 2.5 \%$, which features a good flow ability and no occurrence of particle segregation. Only the surface layer of the tailings deposition shows the development of a flow regime.

After several days of drying and solidifying, the thickened tailings present a good suppression to dust and resistance to the flood scouring by rainfall.

\section{Bibiography}

Feng, M. 2014, 'Introduction to the surface disposal of high density and paste tailings', Second Technical Seminar on Mineral Slurry

Pipeline Transportation and Tailings Dry-type Disposal, Baotou.

Feng, M. 2014, 'Introduction to the dry-type disposal design of Baogang Baiyun West Mine tailings and its effect evaluation', Second 
Technical Seminar on Mineral Slurry Pipeline Transportation and Tailings Dry-type Disposal, Baotou.

Jewell, R.J. and Fourie, A.B. 2006, 'Paste and Thickened Tailings-A Guide', Australian Centre for Geomechanics, Perth, Western Australia.

Pipeline System Incorporated (PSI) 2008, Onsite paste pilot plant testing and thickener sizing study report. 